\title{
Does Elevated Intrabolus Pressure Predict Esophageal Stasis in Dysphagia Patients?
}

\author{
Yu Kyung Cho \\ Department of Internal Medicine, The Catholic University of Korea, College of Medicine, Seoul, Korea
}

\author{
Article: Elevated intrabolus pressure predicts abnormal timed barium esophagram in esophagogastric junction outflow \\ obstruction \\ Hoscheit M, Gabbard S \\ (J Neurogastroenterol Motil 2019;25:521-524)
}

Esophagogastric junction outflow obstruction (EGJOO) is a motility disorder with a heterogenous group of underlying etiologies. It is a manometric diagnosis. The high-resolution manometry (HRM) findings of EGJOO include an elevated median integrated relaxation pressure (IRP) $\geq 15 \mathrm{mmHg}$ of liquid test swallows with preserved peristalsis. ${ }^{1}$ The majority of these disorders involve mechanical obstruction at the esophagogastric junction and other tests such as endoscopy, barium esophagogram, or CT help to evaluate whether obstruction is at the esophagogastric junction or not. Initial evaluation with endoscopy will exclude hiatal hernia, post-surgical changes, and intraluminal processes such as strictures in the distal esophagus and eosinophilic esophagitis before labeling someone with functional EGJOO. The course of EGJOO depends on the underling etiology. For the treatment of primary EGJOO therapies directed at the lower esophageal sphincter are usually needed for patients with persistent symptoms. ${ }^{2}$

The primary or functional EGJOO is used when there is no obvious mechanical cause for the obstruction. In achalasia, the IRP is elevated, but in contrast to EGJOO, there is failed peristalsis or absence of normal peristalsis. ${ }^{1}$ The functional obstruction can cause some degree of bolus stasis. Timed barium esophagram (TBE) is used for the classification of esophageal motility disorders and assessing esophageal function. It is a simple test to measure esophageal bolus transit or anatomical defect. The patient drinks 100-200 $\mathrm{mL}$ of low-density barium sulfate in the upright position. X-ray images are obtained at 1,2 , and 5 minutes. ${ }^{3}$ TBE has its greatest value in differentiating non-treated achalasia from EGJOO. A recent study done by Blonski et al ${ }^{4}$ showed that the barium height of $5 \mathrm{~cm}$ at 1 minute to have an excellent accuracy with a sensitivity of $94 \%$ and specificity of $71 \%$ in differentiating non-treated achalasia from EGJOO. ${ }^{4}$ However, TBE does not eliminate the need for HRM in cases of EGJOO due to poor accuracy of liquid barium to differentiate EGJOO from non-achalasia dysphagia. They proposed that cutoff values of barium column height ( $\geq 5 \mathrm{~cm}$ at 1 minute and $\geq$ $2 \mathrm{~cm}$ at 5 minutes) to separate untreated achalasia from EGJOO. ${ }^{4}$

In contrast, Hoscheit and Gabbard ${ }^{5}$ reported contradictory results from a previous study. They evaluated this relationship between TBE and HRM in patients with EGJOO. They also evaluated which of HRM metrics may indicate EGJ abnormal barium stasis in TBE. More than $50 \%$ of patients of functional EGJOO had a persistent barium column. Patients with abnormal TBE were found to have significantly elevated intrabolus pressure (IBP)

Received: September 18, 2019 Revised: None Accepted: September 19, 2019

() This is an Open Access article distributed under the terms of the Creative Commons Attribution Non-Commercial License (http://creativecommons. org/licenses/by-nc/4.0) which permits unrestricted non-commercial use, distribution, and reproduction in any medium, provided the original work is properly cited.

*Correspondence: Yu Kyung Cho, MD, PhD Department of Internal Medicine, The Catholic University of Korea, College of Medicine, Seoul St. Mary's Hospital, Banpodaero 222, Seochogu, Seoul 06591, Korea Tel: +82-2-2258-2064, Fax: +82-2-2258-2055, E-mail: ykcho@catholic.ac.kr 
compared with patients who had a normal TBE. Why are the results different from the Blonski's study? First, this study enrolled a small population. Second, the early achalasia or achalasia variant with preserved peristalsis might be classified as EGJOO, therefore, some patients would show barium stasis. Third, the definition of abnormal TBE was different and only defined the barium height at 5 minutes.

In this study, patients with abnormal TBE had no differences in IRP but significantly elevated IBP in comparison to those with a normal TBE. All patients with delayed emptying at 5 minutes had an intrabolus pressure greater than $24 \mathrm{mmHg}{ }^{5}$

In summary, there is the role of TBE in defining the esophageal function or bolus stasis in EGJOO. If whether elevated IBP on HRM may be predictive of abnormal barium emptying in TBE or not should defined in further studies.

\section{Financial support: None.}

\section{Conflicts of interest: None.}

\section{References}

1. Kahrilas PJ, Bredenoord AJ, Fox M, et al. The Chicago Classification of esophageal motility disorders, v3.0. Neurogastroenterol Motil 2015;27:160-174.

2. Samo S, Qayed E. Esophagogastric junction outflow obstruction: Where are we now in diagnosis and management? World J Gastroenterol 2019;25:411-417.

3. de Oliveira JM, Birgisson S, Doinoff C, et al. Timed barium swallow: a simple technique for evaluating esophageal emptying in patients with achalasia. AJR Am J Roentgenol 1997;169:473-479.

4. Blonski W, Kumar A, Feldman J, Richter JE. Timed barium swallow: diagnostic role and predictive value in untreated achalasia, esophagogastric junction outflow obstruction, and non-achalasia dysphagia. Am J Gastroenterol 2018;113:196-203.

5. Hoscheit M, Gabbard S. Elevated intrabolus pressure predicts abnormal timed barium esophagram in esophagogastric junction outflow obstruction. J Neurogastroenterol Motil 2019;25:521-524. 